\title{
A stumbling block or a stepping stone?
}

\author{
F.M. Zimmermann ${ }^{1} \cdot$ L.R. Dekker ${ }^{1}$
}

Published online: 15 February 2016

(C) The Author(s) 2016. This article is published with open access at Springerlink.com

\section{Question}

A 60-year-old man, known with Fabry disease, secondary left ventricular hypertrophy, and moderate aortic valve stenosis had a check-up in the outpatient clinic. An electrocardiogram (ECG) at rest (Fig. 1) showed sinus rhythm, a short PR interval, QRS interval of $120 \mathrm{~ms}$ with a sharp initial part suggestive of pre-excitation, as well as other unchanged abnormalities, including signs of left ventricular hypertrophy. In order to examine this possible pre-excitation suggestive of a right-sided, septal bypass an exercise test was performed. Unfortunately, the test was stopped after only 2 min due to exhaustion with a maximal heart rate of only 83/minute, without changes in QRS morphology. Because of a negative history of collapse or palpitations no further diagnostic tests were performed. Four months later, he was admitted because of a collapse. The ECG at presentation is shown in Fig. 2.

What is your diagnosis, and what does it tell you about the possible pre-excitation?

\section{Answer}

You will find the answer elsewhere in this issue.

Open Access This article is distributed under the terms of the Creative Commons Attribution 4.0 International License (http://creativecommons.org/licenses/by/4.0/), which permits unrestricted use, distribution, and reproduction in any medium, provided you give appropriate credit to the original author(s) and the source, provide a link to the Creative Commons license, and indicate if changes were made.
F.M. Zimmermann

Frederik.zimmermann@catharinaziekenhuis.nl

Department of Cardiology, Catharina Hospital Eindhoven, Eindhoven, The Netherlands 
Neth Heart J (2016) 24:296-297

297

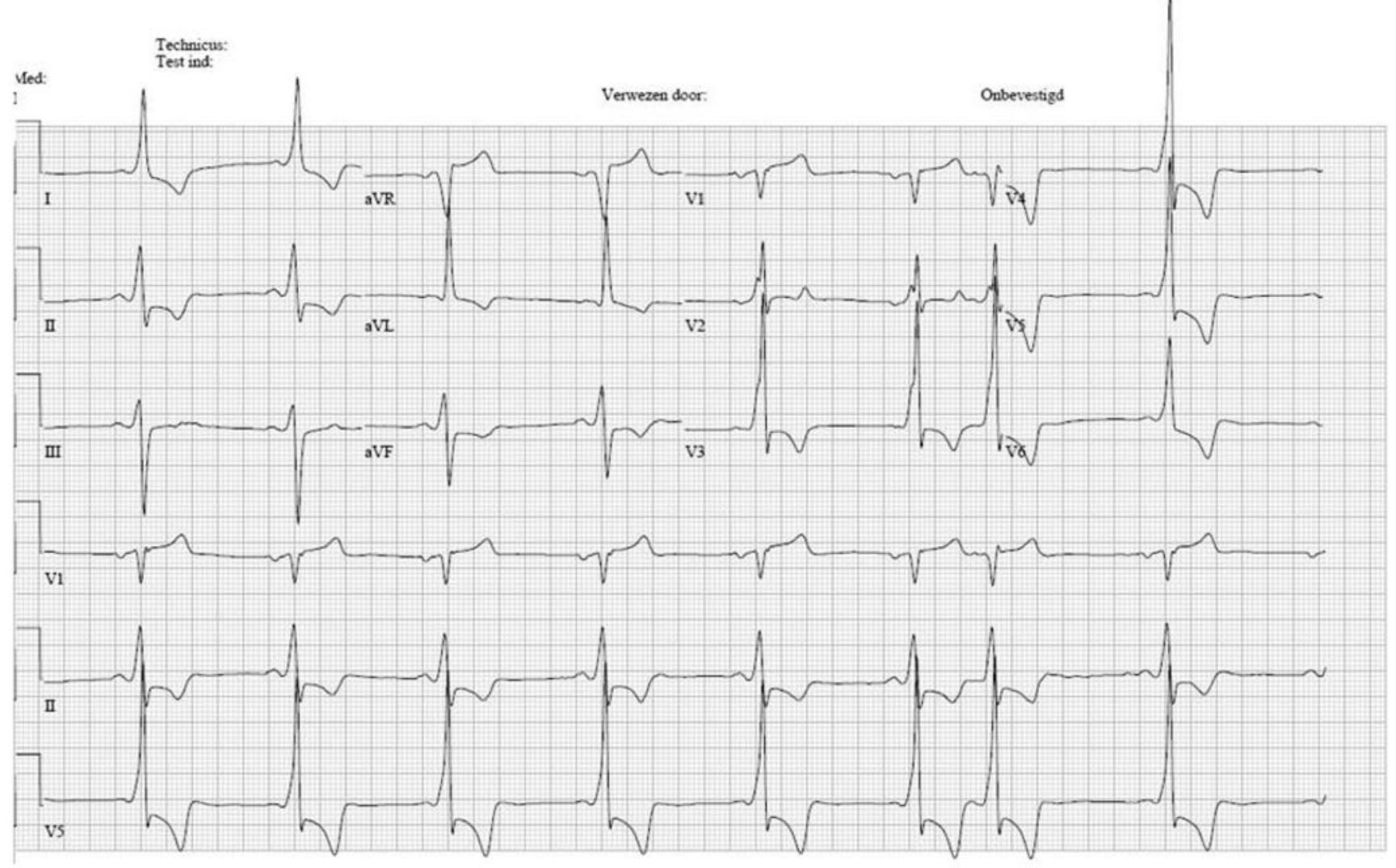

Fig. 1 ECG at rest

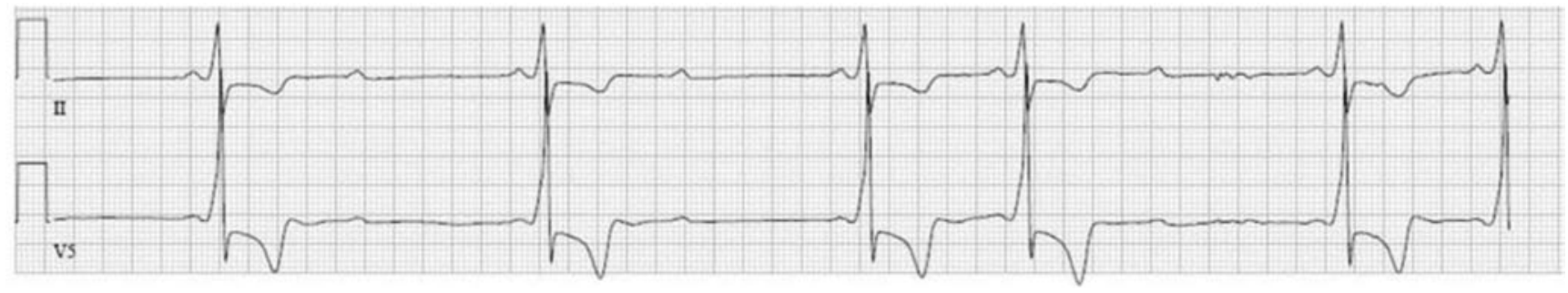

Fig. 2 ECG in the emergency room

SS 